\title{
Treatment of congenital mesoblastic nephroma at pediatric oncology unit of Gabriel Toure teaching hospital.
}

\section{Fousseyni Traore'*, Belco Maiga', Konimba Diabaté2 ${ }^{2}$ Yacaria Coulibaly ${ }^{3}$, Hawa Diall', Pierre Togo', Oumar} Coulibaly', Issa Amadou', Karamoko Sacko', Abdoul Karim Doumbia', Abdoul Aziz Diakite', Bakary Kamaté4, Fatoumata Dicko-Traoré', Mariam Sylla', Boubacar Togo'

'Gabriel Toure hospital, department of pediatrics, Bamako-Mali

${ }^{2}$ National hospital of Mali, Radiation therapy service, Bamako-Mali

${ }^{3}$ Gabriel Toure hospital, pediatric surgery service, Bamako-Mali

${ }^{4} \mathrm{Hospital}$ of Point G, department of histopathology, Bamako-Mali

\section{Article Info}

\section{Article Notes}

Received: April 24, 2018

Accepted: May 24, 2018

\section{*Correspondence:}

Dr. Fousseyni Traore

1 Gabriel Toure hospital, department of pediatrics, BamakoMali; Telephone: (00223) 66748262

Email: drfousseynitraore@gmail.com

() 2018 Traore F. This article is distributed under the terms of the Creative Commons Attribution 4.0 International License.

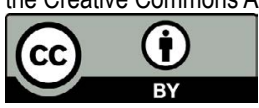

\section{Keywords}

Congenital mesoblastic nephroma

Children

Mali

\section{ABSTRACT}

Purpose: Congenital mesoblastic nephroma $(\mathrm{CMN})$ is a mesenchymal renal tumor of the newborn and young infant. This tumor is generally non-aggressive and amenable to surgical removal. Few studies are available in Africa about the treatment of CMN. The aim of this retrospective study was to evaluate the treatment of $\mathrm{CMN}$ in the pediatric oncology unit of teaching hospital Gabriel Toure in Bamako-Mali.

Patients and method: The study was performed retrospectively from 01 January 2005 to 31 December 2016 (duration 11 years), in the pediatriconcology unit of Gabriel Touré Teaching Hospital. Were included, patients with histologically proven CMN. The uretero-nephrectomy was indicated for all included patients. Patients with significant tumor volume at abdominal CT-scan and those with no staging at surgery with imprecise histologic stage, received neoadjuvant and adjuvant chemotherapy, respectively.

Result: From 2005/01/01 to 2016/12/31 eight cases of CMN were included in the study. CMN accounted for $3 \%$ of renal tumors. The median age of patient was 4.5 months ( 1 month- 6 months) with a sex ratio of $0.33(M=2, F=6)$. Abdominal mass was the most common physical sign $(n=7 ; 87 \%)$. The CT scan was performed in five patients (62\%). There was no difference in laterality (right kidney, $n=4$, left kidney, $n=4$ ).

Three patients received neoadjuvant chemotherapy (37\%). Seventytwo percent of patients received initial nephro-ureterectomy. The histology confirmed $\mathrm{CMN}$ in all patients ( $\mathrm{n}=8,100 \%$ ). All patients had the classic histological form ( $n=8 ; 100 \%)$. Stage $1(n=4 ; 50 \%)$, stage $2(n=2 ; 25 \%)$, unspecified $(n=2 ; 25 \%)$. Two patients received adjuvant chemotherapy $(25 \%)$. Overall survival was $100 \%$ with a median follow-up of 8 years $(6-10$ years).

Conclusion: Multidisciplinary collaboration is the key of therapeutic success of $\mathrm{CMN}$.

\section{Introduction}

Congenital Mesoblastic Nephroma (CMN) is a renal tumor of the newborn and young infant. This tumor was first described by Bolande in 1967 as a distinct tumor from nephroblastoma by its histological, therapeutic and prognostic features ${ }^{1}$. It is classically considered benign, and most often, only the surgical treatment is enough for its management. CMN occurs in $90 \%$ of cases before one year of age and in $60 \%$ of cases before 4 months $^{2}$. It accounts for 
$3 \%$ to $4 \%$ of pediatric renal tumors ${ }^{3}$. Obstetric ultrasound permits to make in utero diagnosis ${ }^{4}$. Histologically, there are three variants of this tumor: the classical form, the cellular and mixed form (Fig.1). Abdominal ultrasound and CT scan are commonly used radiological examinations. Ultrasound appearance can vary depending on the pathological variant. In general it is a well-defined mass with low-level homogeneous echoes. The abdominal CT scan shows a solid hypoattenuating renal lesion with variable contrast enhancement (Fig.2).The clinicalhistological correlation and the prognosis of the disease have not been demonstrated ${ }^{5,6}$. And in Africa, in general, few studies have been carried out on CMN. In this study, we report our experience on the management of this tumor at the pediatric oncology unit of teaching hospital Gabriel Toure.

\section{Objectives}

This retrospective study aimed at evaluating the

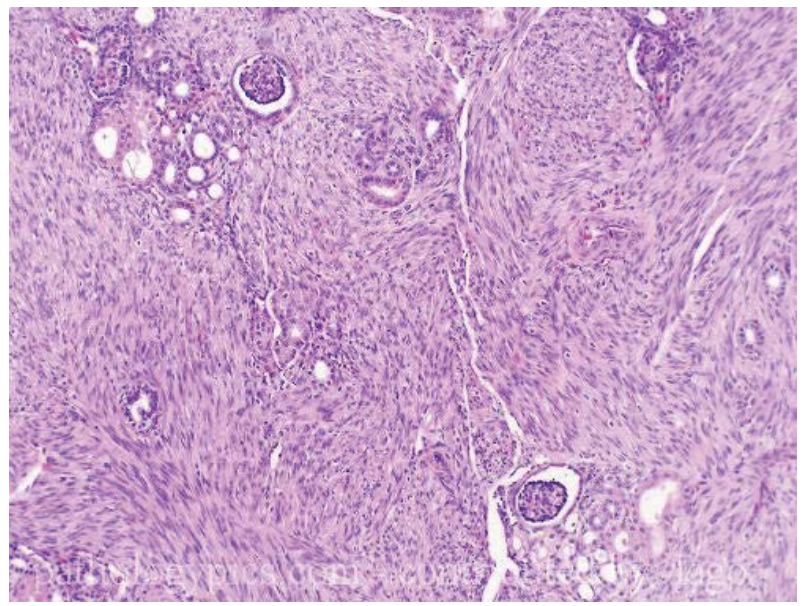

Fig.1: Histological feature of Classical CMN

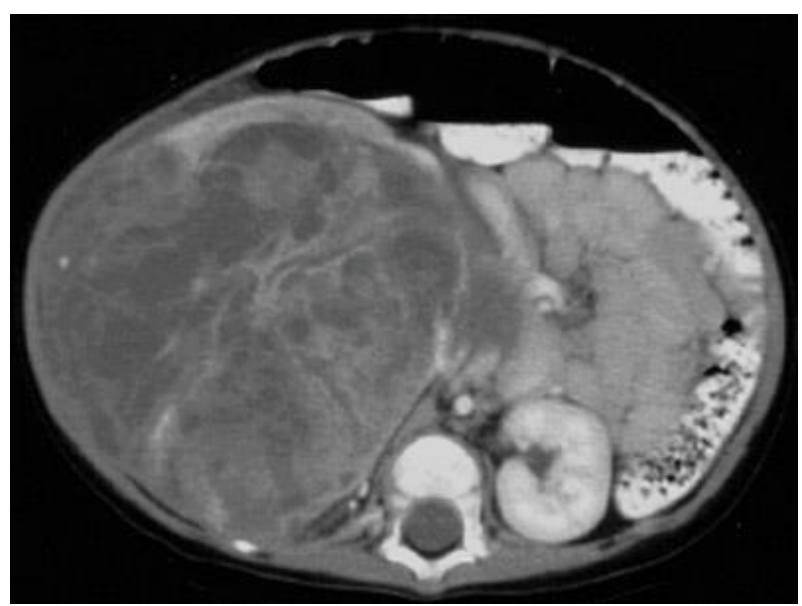

Fig.2: the abdominal CT scan of a right kidney $\mathrm{CMN}$ in a 5 month old boy. epidemiological, therapeutic and evolutive aspects of children treated for CMN.

\section{Patients and methods}

The study was performed retrospectively from 01 January 2005 to 31 December 2016 (duration 11 years), in the pediatric-oncology unit of Gabriel Touré Teaching Hospital. Were included, patients with histologically proven CMN. Parents or legal guardian consent has been obtained. All patients had a complete clinical oncology evaluation combined with CBC (complete blood count) routine check, echocardiography, renal and hepatic function tests, HIV (human immunodeficiency virus), HbsAg (hepatitis B virus), Rhesus grouping, serum electrolytes, and haemoglobin electrophoresis. The Z-score on WHO's growth standards (weight-height score according to age of children) was used to evaluate the nutritional status of the patients. Abdominal computed tomography (CT scan) with contrast was also performed on all patients. The data was collected from medical records.

Treatment strategy: Enlarged uretero-nephrectomy was indicated in all included patients. Patients with significant tumor volume at abdominal CT-scan and those with no staging at surgery and imprecise histologic stage, received neoadjuvant (Vincristine $1,5 \mathrm{mg} / \mathrm{m}^{2} \mathrm{IV}$, once a week, during 4 weeks; Actynomycin-D $45 \gamma / \mathrm{kg}$ IV, on week 1 and 4) and adjuvant chemotherapy (Vincristine 1, $5 \mathrm{mg} /$ $\mathrm{m}^{2} \mathrm{IV}$, once a week, during 8 weeks; Actynomycin-D $45 \mathrm{\gamma} /$ $\mathrm{kg}$ IV, on weeks 3 and 7), respectively. The chemotherapy regimen is based on "GFA Nephro 2005" of the FrancoAfrican Group of Pediatric Oncology (GFAOP).

Definition of the response criteria: Complete remission was defined as the disappearance of any clinical and biological signs with imagery without signs of tumor in progression. Relapse has been defined as the reappearance of the tumor regardless of the site.

Patient monitoring after surgery was done with a thoraco-abdominal CT scan, performed at 6 months, 1 year, and once a year for 3 years.

Statistical analysis: The follow-up time for each patient was counted from inclusion in the study to the latest information. For overall survival (OS), all deaths were counted regardless of the cause and the survival times of the living patients were censored at the time of closure. Data from the included patient medical records was analyzed on SPSS version 20 (SPSS Inc., Chicago, IT).

\section{Results}

Eight cases of CMN were included. It accounted for 3\% of renal tumors $(n=251)$ during the same period. The median age was 4.5 months ( 1 month- 6 months) with a sex ratio of $0.33(M=2, F=6)$. Sixty-two percent of the patients had a low socioeconomic status; twenty-five percent of patients 
had medical insurance $(\mathrm{n}=2)$. Antenatal ultrasonography was normal in all patients. Abdominal mass was the most common physical sign $(n=7 ; 87 \%)$. One patient presented the association of abdominal mass and hematuria $(\mathrm{n}=1$; $12.5 \%)$. Computed tomography was performed in five patients $(62 \%)$ and abdominal ultrasonography in three patients (37\%). There was no difference according to the laterality (right kidney, $\mathrm{n}=4$; left kidney, $\mathrm{n}=4$ ). Three patients with significant tumor volume have received neoadjuvant chemotherapy (37\%). Five patients received primary nephro-ureterectomy $(\mathrm{n}=5 ; 62 \%)$. The surgery was performed without incident in $75 \%$ of the cases. CMN with the classic histological form was confirmed in all patients ( $\mathrm{n}=8,100 \%)$. The histological stages were as follows: stage $1(\mathrm{n}=4 ; 50 \%)$, stage $2(\mathrm{n}=2 ; 25 \%)$, unspecified $(\mathrm{n}=2$; $25 \%)$. Two patients have received adjuvant chemotherapy (25\%), with $11 \%$ toxicity (18 courses): neutropenia grade $3(n=2)$ and anemia grade $3(n=2)$. All patients were in complete remission after the treatment and no relapse has been noticed. Overall survival was $100 \%$ with a median follow-up of 8 years (6 -10 years). The characteristics of the patients are summarized in Table 1.

\section{Discussion}

CMN is a renal tumor considered as benign, occurring in $90 \%$ of cases before the age of one year. It represents $3 \%$ to $4 \%$ of pediatric renal tumors ${ }^{7}$, which are found in our series. The median age in our series is 4.5 years with female predominance. Exceptionally the tumor can be diagnosed in the old child and sometimes even in the adult. The male sex is predominant in several series ${ }^{8,9}$. The presence of an abdominal mass of renal origin remains the major symptom in $\mathrm{CMN}^{10}$. Antenatal diagnosis is currently feasible from the second trimester of pregnancy ${ }^{11}$. None of our patients had an antenatal diagnosis. The diagnosis in neonate or in infant is most often made after the palpation of an abdominal mass. The etiological research of arterial hypertension in the infant can often lead to the diagnosis. Radiographically, ultrasound and CT-scan have an important role $^{12,13}$. CT-scan provides a better understanding of the extent of the disease (abdomen, lungs and brain). Sixty-two percent of our patients had CT-scan. Concerning laterality, there was no difference in our patients. This identical distribution is found in the studies of Bayindir and England $\mathrm{RJ}^{14,15}$. Surgery remains the main therapeutic option of the CMN. Neoadjuvant chemotherapy remains exceptional in the CMN. Its goal is to obtain a tumor reduction to facilitate excision. Thirty-seven percent of our patients with significant tumor volume at diagnosis received neoadjuvant chemotherapy. Neoadjuvant chemotherapy has been indicated in patients with significant tumor volume at diagnosis. It allowed tumor reduction, allowing enlarged nephrectomy without any surgical complications. Bayindir and England RJ have reported $20 \%$ and $4 \%$ preoperative

\begin{tabular}{|c|c|c|}
\hline Characteristics & Number & Percentage (\%) \\
\hline \multicolumn{3}{|l|}{ gender } \\
\hline Male & 2 & 25 \\
\hline Female & 6 & 75 \\
\hline \multicolumn{3}{|l|}{ Age (months) } \\
\hline Range & $1-6$ & 100 \\
\hline Median & 4,5 & 75 \\
\hline \multicolumn{3}{|l|}{ Clinical presentation } \\
\hline Abdominal mass & 7 & 87 \\
\hline Abdominal mass + Hematuria & 1 & 12,5 \\
\hline \multicolumn{3}{|l|}{ Imaging } \\
\hline CT-scan & 5 & 62 \\
\hline Abdominal ultrasound & 3 & 37 \\
\hline \multicolumn{3}{|l|}{ Chemotherapy } \\
\hline Neoadjuvant & 3 & 37 \\
\hline Adjuvant & 2 & 25 \\
\hline \multicolumn{3}{|l|}{ Surgery } \\
\hline Nephro-ureterectomy & 8 & 100 \\
\hline \multicolumn{3}{|l|}{ Surgical stage } \\
\hline Stage I & 6 & 75 \\
\hline Unknown & 2 & 25 \\
\hline \multicolumn{3}{|l|}{ Histological stages } \\
\hline Stage I & 4 & 50 \\
\hline Stage II & 2 & 25 \\
\hline Unknown & 2 & 25 \\
\hline \multicolumn{3}{|l|}{ Histological Forms } \\
\hline Classical Form & 8 & 100 \\
\hline \multicolumn{3}{|l|}{ Chemotherapy toxicity } \\
\hline Toxic death & 0 & 0 \\
\hline Grade III Anemia & 2 & 11 \\
\hline Grade III Neutropenia & 2 & 11 \\
\hline \multicolumn{3}{|l|}{ Outcome of patients } \\
\hline Complete remission & 8 & 100 \\
\hline
\end{tabular}

Tab.1: Patients characteristics

chemotherapy respectively in their series ${ }^{14,15}$. Nephroureterectomy was performed in all our patients. The precision of the surgical and histological stage is crucial for further postoperative treatment. Adjuvant chemotherapy has been performed on two patients (25\%) due to unclear surgical and histological stage in our series. Sandstedt reports $17 \%$ postoperative chemotherapy in 29 patients treated for $\mathrm{CMN}^{16}$. The classic histological form was found in all our patients $(100 \%)$. It remains predominant in the literature and is made of fusiform cells, of the fibroblast and myofibroblast types, intertwined ${ }^{17}$. Genetic abnormalities related to CMN have been reported. These abnormalities are found in chromosomes $8,11,17$ and 20. In the cellular form of CMN, a translocation $(12 ; 15)$ was found, resulting in the formation of an ETV6-NTRK3 fusion gene ${ }^{18,19,20}$. The genetic study of our cases has not been done for lack of means. The overall survival of our patients is $100 \%$ with a median follow-up of 8 years ( $6-10$ years). This result is similar to those found in other series ${ }^{14,15,21}$. 


\section{Conclusion}

CMN is a common kidney benign tumor in infants under six months of age. Multidisciplinary collaboration is the key of therapeutic success of this tumor.

\section{Conflicts of interest}

The authors declare that they have no conflicts of interest in relation to this article.

\section{Acknowledgments}

We thank the Frenh-African Group of Pediatric Oncology (GFAOP) for their support.

\section{References}

1. Bolande RP, Brough AJ, Izant RJ. Congenital mesoblastic nephroma of infancy: a report of 8 cases and the relationship to Wilm's tumor. Pediatrics. 1967; 40: 272-8.

2. Richard D, Glick $M$, Jhon $H$, et al. Renal tumors in infants less than 6 months of age. Journal of pediatric surgery. 2004; 39: 522-5.

3. Lefi M, Jouini R, Guesmi M, et al. Congenital nephroblastic nephroma. Prog Urol. 2002; 12: 663-5.

4. Stefan S, Jan L, Harald R, et al. Prenatal diagnosis of congenital mesoblastic nephroma associated with renal hypertension in a premature child. International journal of urology. 2004; 11: 50-1.

5. Sandstedt B, Delemarre JFM, Krul EJ, et al. Mesoblastic nephromas: a study of 29 tumours from the SIOP nephroblastoma file. Histopathology. 1985; 9: 741-750.

6. Bera G, Das RN, Bisht J, et al. Cytological diagnosis of mesoblastic nephroma: A report of three cases with summary of prior published cases. Diagn Cytopathol. 2016; 44: 823-7.

7. Lefi M, Jouini R, Guesmi M, et al. Congenital nephroblastic nephroma Prog Urol. 2002; 12: 663-5.

8. Furtwaengler R, Reinhard H, Leuschner I, et al. Gesellschaft fur Pädiatrische Onkologie und Hämatologie (GPOH) Nephroblastoma Study Group. Mesoblastic nephroma- a report from the Gesellschaft fur Pädiatrische Onkologie und Hämatologie (GPOH). Cancer. 2006; 106: $2275-83$
9. Saula PW, Hadley GP. Pediatric non-Wilms' renal tumors: a third world experience. World J Surg. 2012; 36: 565-72.

10. Howell CG, Othersen HB, Kiviat NE, et al. Therapy and outcome in 51 children with mesoblastic nephroma: a report of the National Wilms' Tumor Study. J Pediatr Surg. 1982; 17: 826-31.

11. Leclair MD, El-Ghoneimi A, Audry G, et al. The outcome of prenatally diagnosed renal tumors. J Urol. 2005; 173: 186-9.

12. Schild RI, Plath $H$, Hofstaetter $C$, et al. Diagnosis of a fetal mesoblastic nephroma by 3D-ultrasound. Ultrasound Obstetric Gynecology. 2000; 15: 533-6.

13. Wootton SL, Rowen SJ, Griscom MT. Pediatric case of the day. Radiographics. 1991; 11: 719-21.

14. Bayindir P, Guillerman RP, Hicks MJ, et al. Cellular mesoblastic nephroma (infantile renal fibrosarcoma): institutional review of the clinical, diagnostic imaging, and pathologic features of a distinctive neoplasm of infancy. Pediatr Radiol. 2009; 39: 1066-74.

15. England RJ, Haider N, Vujanic GM, et al. Mesoblastic nephroma: a report of the United Kingdom Children's Cancer and Leukaemia Group (CCLG). Pediatr Blood Cancer. 2011; 56: 744-8.

16. Sandstedt B, Delemarre JF, Krul EJ, et al. Mesoblastic nephromas: a study of 29 tumours from the SIOP nephroblastoma file. Histopathology. 1985; 9: 741-50.

17. Gruver AM, Hansel DE, Luthringer DJ, et al. Congenital mesoblastic nephroma. J Urol. 2010; 183: 1188-9.

18. El Demellawy D, Cundiff CA, Nasr A, et al. Congenital mesoblastic nephroma: a study of 19 cases using immunohistochemistry and ETV6-NTRK3 fusion gene rearrangement. Pathology. 2016; 48: 47-50.

19. El Demellawy D, Cundiff CA, Nasr A, et al. Congenital mesoblastic nephroma: a study of 19 cases using immunohistochemistry and ETV6-NTRK3 fusion gene rearrangement. Pathology. 2016; 48(1): 47-50

20. Anderson J, Gibson S, Sebire NJ. Expression of ETV6-NTRK in classical, cellular and mixed subtypes of congenital mesoblastic nephroma. Histopathology. 2006; 48: 748-53.

21. L Sahnoun A, Ksia WB, Mansour R, et al. Trois observations de néphrome mésoblastique avant l'âge de 6 mois. African Journal of Urology. 2014; 20: 161-164. 